\title{
CARMELO LISÓN TOLOSANA Y LA REAL ACADEMIA DE CIENCIAS MORALES Y POLÍTICAS
}

\author{
Carmelo Lisón Tolosana and the Royal Academy of Moral \\ and Political Sciences
}

\section{Carmelo Lisón Tolosana e a Real Academia de Ciências Morais e Politicas}

Pablo RAMírez JEREZ

Bibliotecario de la Real Academia de Ciencias Morales y Políticas

biblioteca@racmyp.es

Fecha de recepción: 12/01/2021

Fecha de aceptación:12/02/2021

RESUMEN: Este artículo analiza la figura de Carmelo Lisón Tolosana como académico de número de la Real Academia de Ciencias Morales y Políticas, institución en la que fue admitido en 1992 y en la que desarrolló una amplia actividad intelectual a través de sus numerosas asistencias y en su papel como Bibliotecario de la misma.

Palabras clave: Carmelo Lisón Tolosana; Real Academia de Ciencias Morales y Políticas; Antropología; Bibliografía antropológica.

ABSTRACT: This paper assesses the experience of Carmelo Lisón Tolosana as a full member of the Royal Academy of Moral and Political Sciences, an institution he entered in 1992 and where he deployed an intense intellectual activity through his regular assistance and his role as Academic Librarian.

Key words: Carmelo Lisón Tolosana; Royal Academy of Moral and Political Sciences; Anthropology; Anthropological bibliography. 
RESUMO: Este artigo analisa a figura de Carmelo Lisón Tolosana como membro titular da Real Academia de ciências Morais e Políticas, instituição na qual foi admitido em 1992 e na qual desenvolve uma ampla atividade intelectual através de suas numerosas assistências e em seu papel como Bibliotecário da mesma.

Palavras-chave: Carmelo Lisón Tolosana; Real Academia de Ciências Morais e Políticas; Antropologia; Bibliografia antropológica.

\section{La Real ACADemia de Ciencias Morales y Políticas}

La Real Academia de Ciencias Morales y Políticas fue fundada en virtud de la Ley de Instrucción Pública de 9 de septiembre de 1857, que dispuso «la creación en Madrid de otra Real Academia igual en categoría a las cuatro existentes, denominada de Ciencias Morales y Políticas». Esas cuatro son la Española, la de la Historia, Bellas Artes de San Fernando, y Ciencias Exactas Físicas y Naturales. El objetivo fundamental de la Academia, constituida legalmente el 30 de septiembre de 1857, es «cultivar las Ciencias Morales y Políticas, ilustrando las cuestiones de mayor importancia, transcendencia y aplicación según los tiempos y las circunstancias». El art. 10 establece además que «la Academia elegirá sus miembros de todas clases entre las personas que se distingan por sus conocimientos en los ramos de la Corporación y que considere más dignas».

Carmelo Lisón -D. Carmelo, como le conocíamos en la Academia- fue elegido miembro de número el 20 de noviembre de 1990 para la medalla número 2, vacante por el fallecimiento de Carmelo Viñas y Mey; fue propuesto para dicha medalla por los académicos Juan Velarde, Antonio Truyol y Salustiano del Campo, y tomó posesión de su plaza el 4 de febrero de 1992 con un discurso titulado La imagen del rey: Monarquía, realeza y poder ritual en la Casa de los Austrias, siendo respondido en nombre de la corporación por Salustiano del Campo. Poseyeron esa medalla antes que él los académicos Lorenzo Arrazola, Antonio Cánovas del Castillo, Juan Valera, Eduardo Dato, José Sánchez Guerra, Rufino Blanco, José Jorro Miranda y el citado Carmelo Viñas y Mey.

Los académicos se dividen en secciones según su especialidad, y D. Carmelo quedó adscrito a la sección III, Ciencias Sociales, que en el momento de su ingreso estaba compuesta por Laureano López Rodó, Manuel Alonso Olea, Primitivo de la Quintana López, Salustiano del Campo, Fernando Garrido Falla y Antonio Garrigues y Díaz-Cañabate (entonces la Academia la formaban 36 académicos). En el curso 2019-2020 esa misma sección estaba constituida por los académicos Salustiano del Campo, Carmelo Lisón, Marcelino Oreja, Julio Iglesias de Ussel, Alejandro Nieto, Fernando Suárez, Ricardo Sanmartín, Emilio Lamo de Espinosa, Benigno Pendás, Juan Díez Nicolás y Fernando Vallespín (la nómina actual es de 44 académicos).

Asiduo asistente a las sesiones que se celebran todos los martes del curso, ocupó D. Carmelo dos cargos académicos, siendo Censor entre 1994 y 2002 y 
Bibliotecario entre 2002 y 2011; ambos puestos le permitían estar presente en las reuniones de la mesa directiva y participar en la toma de las decisiones más relevantes de la vida académica. Las atribuciones y obligaciones del Censor son: velar por la observancia de los estatutos y acuerdos; recordar a los académicos el desempeño de las comisiones y trabajos que tengan a su cargo; informar sobre los escritos y asuntos que la Academia someta a su examen; e intervenir las cuentas de Tesorería (art. 22 de los Estatutos).

Por otro lado, durante sus años como académico Bibliotecario se catalogaron decenas de miles de volúmenes y se inició la digitalización del enorme corpus documental de la Academia, esto es, todas las obras editadas por la institución desde su fundación: Discursos, Discusiones, Debates, Premios, Necrológicas, etcétera. Asimismo, en ese periodo se recibieron como donación las bibliotecas de la Fundación de las Cajas de Ahorros (FUNCAS) y la que perteneció al académico Antonio Truyol Serra, así como los archivos documentales de Rufino Blanco Sánchez y Marcelino Oreja; ambos archivos fueron digitalizados y están a disposición de los investigadores en la página web de la Academia. El año 2007, por otra parte, celebró la Academia su sesquicentenario, y la biblioteca organizó una exposición de libros de su fondo de especial valor y relevancia bibliográfica, como incunables y ediciones de los siglos XVI y XVII. Además, se publicó el libro de Francisco García Craviotto Colección de incunables de la Real Academia de Ciencias Morales y Políticas (Madrid, 2007), con prólogo de D. Carmelo.

Como miembro de número, avaló las candidaturas para académico numerario de Julio Iglesias de Ussel, José Luis García Delgado, José María Segovia de Arana, Helio Carpintero Capell, José Félix Tezanos y Ricardo Sanmartín. También presentó a diversos profesionales españoles y extranjeros para ocupar plaza de académicos correspondientes: Antonio E. Pérez Luño (1993), Davydd James Greenwood (1995), Alberto Martinelli (1997), José Antonio Fernández de Rota (1998), Theodore Caplow (1998), Jean Cuisenier (1999), Juan Carlos Agulla (1999), Rafael Segovia (1999), Eloy Fernández Clemente (2000), Antonio Izquierdo (2000), Juan del Pino Artacho (2000), Pierre Tabatoni (2000), Henri Mendrás (2002), Gerard Chastagnaret (2004), João de Pina Cabral (2005), Bernard Traimond (2006), José María Gómez-Tabanera (2007), María Jesús Buxó Rey (2008), Joaquim Verissimo Serrão (2010), Petra M. ${ }^{a}$ Pérez Alonso-Geta (2012), José Antonio González Alcantud (2013) y Luis Álvarez Munarriz (2014).

Asimismo, representó a la Academia como miembro de diferentes jurados, a saber, Premio Nacional de Historia para los años 1994 a 2000, Premio Reina Sofía (1997), y Premio Elías de Tejada en sus convocatorias II a V; también tomó parte en diversas reuniones del Patronato de la Fundación Elías de Tejada y de la Fundación Antonio Maura. Cabe destacar, por último, su participación en la Comisión para tratar el tema de la detención de Pinochet y contestar a la Academia Chilena (1999). 


\section{EL DISCURSO DE INGRESO DE CARMELO LISÓN}

D. Carmelo fue el primer antropólogo elegido miembro de esta Academia, buena muestra del carácter multidisciplinar de la misma, en la que desde sus comienzos tienen cabida economistas, sociólogos, politólogos, teólogos, filósofos o juristas. Su discurso de ingreso, La imagen del rey: Monarquia, realeza y poder ritual en la Casa de los Austrias, primera pieza documental de su paso por esta casa, le sirvió para recuperar la memoria de otro académico pionero en la investigación del derecho consuetudinario y antropólogo avant la lettre, su admirado Joaquín Costa. Además, le abrumaba la idea de que su medalla había pertenecido a Cánovas y Juan Valera, con quienes sentía una afinidad temática por los temas que trataron en sus libros, ya que Cánovas fue un gran estudioso de la época de los Austrias y Valera un fino observador del costumbrismo y estudioso de la cultura española a través de sus obras. En su discurso estudia D. Carmelo la organización palaciega en la época de los Austrias y el protocolo mayestático que circunda y aísla al soberano; la extraña y rígida etiqueta de la corte es la que estimula al antropólogo, "porque sabe que bajo esa riqueza empírica de múltiples modos formales de comportamiento va a descubrir toda una gama de significados, ideas y valores, un metalenguaje sobre el que levantará una síntesis interpretativa» (Lisón Tolosana, 1992: 15). D. Carmelo aborda el estudio de ese modo de existencia lleno de fantasía, mito, arte y creencia, mostrando todo su bagaje antropológico: "Mundo extraordinario y liminal al que tenemos que acercarnos pertrechados de instrumentos simbólico-conceptuales específicos y de categorías politrópicas y semántico-icónicas si queremos captar la dinámica interna de la realeza, la conexión entre el poder y el ceremonial, las implicaciones políticas de los símbolos culturales y, en un último esfuerzo sintético, la imagen del rey desde la naturaleza simbólico-sagrada del poder ritual» (Lisón Tolosana, 1992: 15). La realeza de entonces "significaba magnificencia, y estaba rodeada de un esplendor y una ceremonia que convertía a la figura del rey en un símbolo polivalente con funcionalidad múltiple y plurales radiaciones expresivas» (Lisón Tolosana, 1992: 15).

\section{Publicaciones de Carmelo Lisón en la Real ACademia de Ciencias Morales Y POLÍTICAS}

Toda la actividad científica de la Academia queda recogida en los Anales de la Real Academia de Ciencias Morales y Políticas, publicación que inició su andadura en 1934 tomando el testigo de las antiguas Memorias y Extractos de Discusiones que se publicaron hasta 1926. Así pues, es en los Anales donde se encuentran las ponencias que cada martes del curso académico leen los académicos. D. Carmelo contribuyó puntualmente a la producción científica de la Academia con ponencias que presentó cada año desde 1992 hasta 2018; se encargó igualmente de redactar la biografía de Joaquín Costa para la colección "Académicos vistos por académicos» 
(Madrid, 1997), a la que agregó el subtítulo Notas para la etopeya de un pionero, y del discurso de contestación al académico Ricardo Sanmartín, titulado Imágenes de la libertad y figuración antropológica en el horizonte de nuestra época. En este último caso, además de presentar al nuevo académico y sus méritos, D. Carmelo se explaya en la descripción del ritual de recepción, se ve inmerso en uno de sus campos predilectos de estudio y aprovecha la ocasión para ofrecer a los asistentes una visión antropológica del acto de ingreso de un académico recipiendario.

Sus intervenciones académicas, por orden cronológico y con referencia a su publicación en los Anales de la Academia, son las siguientes:

Racionalidad e Inquisición en el Siglo de Oro.

Anales, n. ${ }^{\circ} 69$ (1992), pp. 67-82.

Viaje por la antropología del extranjero.

Anales, n. 70 (1993), pp. 481-513.

Etnicidad y violencia.

Anales, n. ${ }^{\circ} 71$ (1994), pp. 247-259.

Retablo de máscaras gitanescas (antropología de la diferencia).

Anales, n. ${ }^{\circ} 72$ (1995), pp. 227-251.

Espacios éticos de la enfermedad.

Anales, n. ${ }^{\circ} 73$ (1996), pp. 265-283.

Los cambiantes gestos y flexibles discursos del honor.

Anales, n. 74 (1997), pp. 323-336.

Anatomía de una generación (Ciclo sobre la generación del 98).

Anales, n. ${ }^{\circ} 75$ (1998), pp. 395-410.

El potencial de una idea. Derecha e izquierda en clave antropológica.

Anales, n. ${ }^{\circ} 76$ (1999), pp. 427-442.

Antropología en la frontera de dos siglos (la dialéctica de un continuum).

Anales, n. 77 (2000), pp. 367-378.

La europeización de Europa (Historia cultural selectiva).

Anales, n. 78 (2001), pp. 301-318.

Multiculturalismos (en clave antropológica).

Anales, n. 79 (2002), pp. 389-400.

Anatomía de Europa.

Anales, n. 80 (2003), pp. 619-630.

Máscaras de Europa.

Anales, n. ${ }^{\circ} 80$ (2003), pp. 721-723.

Glosa a Dios en la Constitución.

Anales, n. ${ }^{\circ}$ 81/I (2004) (25 años de la Constitución), pp. 237-240.

Cultura y globalización.

Anales, n. ${ }^{\circ}$ 81/II (2004), pp. 287-294.

La otra vía (Ciencia y razón antropológica).

Anales, n. ${ }^{\circ} 82$ (2005), pp. 161-186.

Conocer y saber. 
Anales, n. ${ }^{\circ} 82$ (2005), pp. 313-317.

Dimensiones Mito-Lógicas de El Quijote.

Anales, n. ${ }^{\circ} 83$ (2006), pp. 21-34.

Modos de ver, maneras de actuar.

Anales, n. ${ }^{\circ} 84$ (2007), pp. 445-454.

El mal es el Otro... y nosotros.

Anales, n. ${ }^{\circ} 85$ (2008), pp. 425-434.

La emergencia de un nuevo mirar hispano (siglos XV y XVI).

Anales, n. 86 (2009), pp. 229-236.

Antropología aplicable.

Anales, n. ${ }^{\circ} 87$ (2010), pp. 55-64.

La gramática cultural del valor (en clave etnográfica).

Anales, n. 88 (2011), pp. 173-180.

Patrimonio cultural, memoria, política y arte.

Anales, n. ${ }^{\circ} 89$ (2012), pp. 435-442.

Occidente y Oriente en el escenario misionero japonés, 1549-1590.

Anales, n. ${ }^{\circ} 90$ (2013), pp. 543-552.

Ontologías líquidas. El argumento por ambigüedad en la cultura gallega.

Anales, n. ${ }^{\circ} 91$ (2014), pp. 5-18.

Humanismo cultural.

Anales, n. ${ }^{\circ} 92$ (2015), pp. 25-32.

El relativismo en argumento cultural.

Anales, n. 93 (2016), pp. 127-134.

El mito (En argumento cultural).

Anales, n. ${ }^{\circ} 94$ (2017), pp. 317-326.

Santa Marta de Ribarteme (a la vida por la muerte, al independentismo por la paradoja).

Anales, n. ${ }^{\circ} 96$ (2019), pp. 15-26.

La celebración de un recuerdo.

Anales, n. ${ }^{\circ} 97$ (2020) [en prensa; conferencia no expuesta oralmente].

La mayor parte de estos textos fueron recogidos en el volumen Carmelo Lisón Tolosana: Intervenciones en la Real Academia de Ciencias Morales y Políticas (1992-2018), publicado por la Fundación Lisón Donald en 2019; también se encuentran disponibles en la página web de la Academia (www.racmyp.es). Merece la pena transcribir parte del prólogo encuadra que el mismo D. Carmelo escribió para este volumen recopilatorio, pues encuadran perfectamente estos trabajos dentro de su visión antropológica:

Estos artículos que celebran la pujanza de la vida y su transformación en narrativa paratáctica, fracturada y digresiva a veces, dibujan algo del predicamento humano en que nos encontramos porque vienen carentes de absolutos últimos y huérfanos de certezas morales generales únicas e indiscutibles, pero también presentan la penetración de las gafas culturales para inferir deseos, sentimientos, opciones y 
pasiones, juicios y valores, significados, ultimidades y sentidos de lo que es y hay, en suma, nuestras vivencias y experiencias. [...] ¿Qué nos revelan hoy estos documentos sobre el momento cultural del ayer? ¿Qué no podrían entender los de ayer de nosotros hoy? El pasado escrito en monumentos, instituciones, ritos, santuarios, calles, signos, imágenes, metáforas y símbolos, y en todo un conjunto de fragmentos enigmáticos está esperando que coloquemos la cultura en el centro de la Historia para que le preguntemos cómo la cultura informa qué y cómo, cómo da sentido a cuestiones vitales como el valor y la verdad. [...] ese pasado está destinado, como campo de fuerzas, a cumplirse ahora. No olvidemos que los mitos viven y, como el rito, operan como terapia cultural y nos alertan de las aporías y misterios a que nos enfrentamos, y de cómo podemos visualizar la historia desde una perspectiva ahistórica y metahistórica. [...] El Otro, el ajeno y extraño, el límite y la frontera son categorías que se nos imponen cuando salimos a la calle; nos impresionan y sorprenden, nos asombran y extrañan, despiertan la voz de la conciencia y nos invitan a reconsiderar ideas canonizadas arraigadas tomando distancia crítica, a oír voces universales aporéticas, a transcender prejuicios y enriquecer nuestra visión. [...] El Otro es sin duda centro de nuestra investigación (Lisón Tolosana, 2019: 9).

Como podemos observar, muchas de las intervenciones son sobre asuntos pedidos ex profeso por la Academia en el marco de un ciclo de conferencias monográfico: "Anatomía de una generación”, sobre la generación del 98; "El potencial de una idea. Derecha e izquierda en clave antropológica", dentro del ciclo monográfico Derechas e Izquierdas en el mundo actual; "Dimensiones Mito-Lógicas de El Quijote»; "Máscaras de Europa”, leída esta en un debate sobre Turquía. En otras ocasiones el artículo sigue el hilo de alguna investigación que D. Carmelo ha realizado o tiene en mente, como el primero de ellos, "Racionalidad e Inquisición en el Siglo de Oro", relacionado con sus estudios sobre la España mental (Vid. Lisón Tolosana, 1990); o las dedicadas a la imagen del otro, en concreto al encuentro de españoles y portugueses con los pueblos asiáticos, como son «Modos de ver, maneras de actuar", "La emergencia de un nuevo mirar hispano" y "Occidente y Oriente en el escenario misionero japonés, 1549-1590", relativos a su obra sobre Japón (Vid. Lisón Tolosana, 2011).

Sobre la ciencia antropológica propiamente dicha cabría citar sus artículos "Retablo de máscaras gitanescas (antropología de la diferencia)", "Antropología en la frontera de dos siglos (la dialéctica de un continuum)", "Multiculturalismos (en clave antropológica)", "Cultura y globalización", "La otra vía (Ciencia y razón antropológica)", "Antropología aplicable», "Humanismo cultural», "El relativismo en argumento cultural» $\mathrm{y}$ "El mito en argumento cultural».

En cambio, sobre Galicia tiene menos intervenciones específicas: «Espacios éticos de la enfermedad", "Ontologías líquidas» y "Santa Marta de Ribarteme»; quizá había vertido ya casi todas sus reflexiones y conocimientos en los numerosos libros y trabajos que dedicó a la antropología cultural gallega.

Su última intervención en la Academia versó sobre Santa Marta de Ribarteme, un estudio sobre la anatomía de la creencia que -escribe- «nos ilumina sobre la 
fuerza de la creencia y la ilusión de neutralidad bajo el manto de la tradición». Y es que D. Carmelo resaltaba el componente existencial de la creencia, esto es, "de cómo queremos vivir aquí y ahora; de aquí que la creencia flote en lugares y momentos concretos y por razones concretas, porque lo que realmente existe en este campo es el todo, el conjunto, el sistema total desde el que decidimos las consideraciones prácticas. [...] Es difícil centrarse en las partes aisladas como la verdad, la intención, la racionalidad, el valor, la realidad, el significado interno y el estándar colectivo porque todo está contaminado por la ortodoxia local que viola con frecuencia la racionalidad y la verdad común». D. Carmelo traslada la lectura antropológica que documentó en Ribarteme al independentismo catalán, en cuanto que «evidencia una actitud mental análoga, inyectada de irrealidad desiderativa, irreductible a términos racionales, cuando los hechos son palmariamente identificables» (Lisón Tolosana, 2019: 458 y sig.).

\section{CONCLUSIÓN}

Como podemos ver al repasar sus intervenciones, a pesar de la amplia variedad de temas que trataba, siempre centraba sus presentaciones en una problemática eminentemente cultural, en cómo se elaboran los conceptos o se construye la realidad, en cómo la realidad cultural necesita de contexto social y temporal para ser interpretada, en definitiva. Todo su esfuerzo académico -escribe en "La celebración de un recuerdo»- ha estado orientado al mundo mental del Otro, al quantum de diversidad, diferencia e hibridez de todo grupo humano; y en este mismo texto, aún inédito, no deja de resaltar la importancia del trabajo de campo, y cómo lo aplicó a lo largo de los meses que él y Julia dedicaron a recorrer Galicia en 1964 y 1965.

La Academia disfrutó de la presencia activa de D. Carmelo durante casi tres decenios, y él mismo encontró aquí un buen acomodo y sólido apoyo para sus trabajos: unos compañeros que le animaban en sus proyectos y una magnífica biblioteca que se enriqueció considerablemente en títulos de antropología gracias a sus atinadas propuestas de adquisiciones, muchas de ellas sacadas de las páginas del Times Literary Supplement, del que era un ávido lector. No faltaba ningún martes a las sesiones de la Academia -se le contabilizaron casi 1.000 asistencias- era de los primeros en llegar y acudía puntualmente a la biblioteca a encargar libros y a organizar sus tareas. Finalmente, cabe decir que varios de sus compañeros de la Academia participaron en diversos actos de la Fundación Lisón Donald, cuyo patronato cuenta también con la presencia de varios académicos.

\section{REFERENCIAS BIBLIOGRÁFICAS}

Lisón Tolosana, C. (1990). Demonios y exorcismos en los Siglos de Oro (La España mental I). Madrid: Akal. 
Lisón Tolosana, C. (1992). La imagen del rey: Monarquia, realeza y poder ritual en la Casa de los Austrias. Madrid: Espasa-Calpe.

Lisón Tolosana, C. (2011). La fascinación de la diferencia. La adaptación de los jesuitas al Japón de los samuráis. Madrid: Akal.

Lisón Tolosana, C. (2019). Intervenciones en la Real Academia de Ciencias Morales y Politicas (1992-2018). La Puebla de Alfindén, Zaragoza: Fundación Lisón Donald, Diputación de Zaragoza.

Sanmartín Arce, R. (2010). Imágenes de la libertad y figuración antropológica en el horizonte de nuestra época. (Discurso de recepción del académico de número y contestación del Excmo. Sr. D. Carmelo Lisón Tolosana. 23 de febrero de 2010. Madrid, Real Academia de Ciencias Morales y Políticas). 
